ENFOQUES JURIDICOS

REVISTA MULTIDISCIPUINAR DEL CEDEGS

ISSN 26832070

Número 03

enero-junio 2021
Reseña: “Litigación climática”

María del Rosario Huerta

DOI: https://doi.org/10.25009/ej.v0i3.2564

\title{
Litigación climática
}

\section{Sabin Center for Climate Change Law at Columbia Law School (2020). Recuperado de https://climate.law.columbia.edu/}

María del Rosario Huerta Lara

Investigadora del Instituto de Investigaciones Jurídicas

Universidad Veracruzana. Xalapa-Equez. Veracruz, México

rhuerta@uv.mx

El incremento de litigios climáticos en el mundo pone de manifiesto que la situación del cambio climático está accediendo a los tribunales de Justicia como última solución para que los gobiernos actúen para mitigar los cada vez más intensos daños al ambiente, adoptando medidas eficaces contra el deterioro climático y la pasividad gubernamental. ¿Habrá también que acudir a los Tribunales? Los Estados tienen la obligación de adoptar medidas para proteger los derechos humanos de los efectos perniciosos del cambio climático y de diseñar marcos jurídicos e institucionales que protejan contra dichos efectos. En México se han expedido algunos instrumentos jurídicos y arreglos institucionales para enfrentar el cambio climático en el país, además de ratificar el Acuerdo de París el 14 de septiembre de 2016 e implementar las metas establecidas en su Contribución Prevista y Determinada a Nivel Nacional, resultados de acuerdos planteados como parte de la Conferencia de las Partes (COP 19) celebrada en Varsovia en el 2013, donde se invitó a las Partes de la Convención a iniciar o intensificar, así como a comunicar sus acciones que llevarán a cabo a nivel nacional para reducir sus emisiones de gases efecto invernadero.

Ante esta situación, en las últimas dos décadas, diferentes actores de la sociedad civil y algunas autoridades públicas vienen abriendo caminos alternativos ante la pasividad de las instituciones políticas. En este sentido, la litigación climática se está convirtiendo en una vía bastante efectiva para obligar a los Estados e incidir en sus políticas climáticas. Precisamente, porque surgen del fracaso de la política frente a los enormes retos de nuestros tiempos. Los litigios climáticos colisionan a menudo con el principio de separación 
ENFOQUES JURIDICOS

REVISTA MULTIDISCIPUNAR DEL CEDECS

ISSN 26832070
Reseña: “Litigación climática”

María del Rosario Huerta

DOI: https://doi.org/10.25009/ej.v0i3.2564

Número 03

enero-junio 2021

de poderes del ámbito federal y estatal, sillares fundamentales del Estado liberal. Esta problemática se torna visible a través del análisis crítico de varios pronunciamientos judiciales de diversos tribunales nacionales e internacionales. Por ello, es de la mayor importancia poder valorar cómo los tribunales han venido delineando el equilibrio entre los distintos poderes del Estado en el proceso de gobernanza del cambio climático y, especialmente, entre los poderes políticos y el poder judicial. Poco se ha considerado el papel del Poder Judicial en la batalla contra el cambio climático. No obstante, los tribunales pueden hacer cumplir las obligaciones que han asumido los Estados y proteger los derechos de quienes se encuentran bajo su jurisdicción. Dado que un porcentaje de los efectos negativos del cambio climático se presentará dentro del territorio mexicano, es necesario utilizar las herramientas disponibles para formular y aplicar medidas de adaptación y mitigación a decuadas frente a este fenómeno.

¿Cómo acceder a información de litigios sobre el cambio climático en los Estados Unidos y fuera de él?

El Sabin Center for Climate Change Law (https://climate.law.columbia.edu/) at Columbia Law School y el Climate Change Litigation of the World of Grantham Research Institute on Climate Change (https://www.Ise.ac.uk/grantham-research-institute) de la London School of Economics and Political Science ${ }^{1}$ han puesto a disposición del público, para su consulta electrónica, dos portales muy completos e interesantes que incluyen dos bases de datos de una dilatada casuística sobre litigación climática cada uno: se trata de un extenso y profuso inventario de casos que han sido parte ante instancias administrativas, judiciales o investigativas, que presentan cuestiones de hecho o de derecho de aspectos científicos del cambio climático o esfuerzos de mitigación y adaptación al cambio climático. "(...) excluye casos donde la discusión sobre el cambio climático es circunstancial e irrelevante para el futuro de la legislación relativa al cambio climático" (PNUMA, 2017, El estado del litigio en materia de cambio climático. Una revisión global. p. 10 y 11).

La base de datos de "casos" de litigios sobre el cambio climático en Estados Unidos, realiza un seguimiento de juicios, demandas y procedimientos administrativos, relacionados con el cambio climático. La Tabla de litigios climáticos de esta base informática, se actualiza cada mes y se basa en más de una década de recopilación de datos por parte del Grantham Research Institute de la LSE y del Sabin Center for Climate Change Law de la Columbia Law School. Actualmente incluye 1282 casos con enlaces a 6783

\footnotetext{
${ }^{1}$ El Instituto de Investigación Grantham sobre el Cambio Climático y el Medio Ambiente fue establecido por la London School of Economics and Political Science en 2008 para crear un centro mundial en investigación y formación sobre el cambio climático y el medio ambiente, reuniendo experiencia internacional en economía, finanzas, geografía, medio ambiente, desarrollo internacional y economía política. Página oficial en https://www.Ise.ac.uk/granthaminstitute/about/about-the-institute/
} 
ENFOQUES JURIDICOS

REVISTA MULTIDISCIPLINAR DEL CEDEGS

ISSN 26832070

Número 03

enero-junio 2021
Reseña: “Litigación climática”

María del Rosario Huerta

DOI: https://doi.org/10.25009/ej.v0i3.2564

documentos. El término "casos" en el gráfico de los Estados Unidos, contiene, además de acciones y procedimientos administrativos judiciales y cuasijudiciales, peticiones de elaboración de normas, solicitudes de reconsideración de reglamentos, avisos de intención de demandas y citaciones. Además, un caso puede implicar múltiples quejas o peticiones que se han consolidado, y la entrada para un solo caso puede incluir múltiples decisiones a nivel de juicio y apelación.

De acuerdo a este portal electrónico, la misión principal del Centro Sabin es desarrollar y promulgar técnicas legales para abordar el cambio climático y capacitar a la próxima generación de abogados que actuaran como representantes legales en el campo. El Centro Sabin es un socio y un recurso para las instituciones legales de interés público, involucradas en el trabajo del cambio climático. Además, el Centro aborda una necesidad crítica para el desarrollo sistemático de técnicas legales para combatir el cambio climático y la recopilación y difusión de información para abogados en los sectores público, privado y de las ONG.

La base de datos sobre legislación, cubre el ámbito judicial de aplicación de las leyes climáticas y relacionadas con el medio ambiente, así como las leyes y políticas que promueven transiciones bajas en carbono. Esto refleja la relevancia de la política climática en áreas que incluyen energía, transporte, uso de la tierra y resiliencia climática. Lo más relevante es el seguimiento y documentación de litigios climáticos en más de 30 países. Estos casos plantean cuestiones de hecho o de derecho con respecto a la ciencia del cambio climático; incluye rubros de políticas o esfuerzos de mitigación y adaptación al cambio climático ante un órgano administrativo, judicial o de investigación. El conjunto de datos permite acceder a información sobre los litigios sobre el cambio climático en los Estado Unidos y fuera de él.

Para el uso y referencia de los datos, los autores fomentan el uso de estas bases informáticas. Los usuarios pueden descargar, guardar o distribuir los resultados electrónicamente o en cualquier otro formato, sin el permiso por escrito de los autores.

- Se puede consultar la fuente de la siguiente manera:

Base de datos, disponible en:

http://climatecasechart.com/

Para consulta de casos en Estados Unidos:

http://climatecasechart.com/us-climate-change-litigation/

Para consulta de casos fuera de EE. UU.

http://climatecasechart.com/non-us-climate-change-litigation/ 
ENFOQUES JURIDICOS

REVISTA MULTIDISCIPLINAR DEL CEDEGS

ISSN 26832070

Número 03

enero-junio 2021
Reseña: “Litigación climática”

María del Rosario Huerta

DOI: https://doi.org/10.25009/ej.v0i3.2564

Leyes de cambio climático del mundo

https://climate-laws.org/

Las ventajas de estos recursos consisten en la apertura de ventanas que permiten comparar el desarrollo de normas y técnicas legales aplicables para combatir el cambio climático y a la vez, prodigar a estudiantes de derecho y abogados en su uso, además de proporcionar a la ciudadanía recursos actualizados sobre temas clave de legislación y regulación climática, que es posible, debido a la estrecha colaboración con los científicos del Earth Institute de la Universidad de Columbia y con organizaciones gubernamentales, no gubernamentales y académicas. Se necesita una estructura legal compleja para inducir y gestionar estas alteraciones. Si bien el derecho ambiental y energético están en el centro de esta estructura, muchas otras áreas del derecho juegan papeles importantes: corporativo, valores, bienes raíces, propiedad, comercio internacional, propiedad intelectual, impuestos, derechos humanos, contratos, penal y otros. La legislación nacional y los acuerdos internacionales dejan muchas cuestiones clave para la implementación de nuevas leyes y reglamentos. Desarrollar el régimen internacional y las leyes marco nacional, resolver los problemas operativos e impulsar los cambios de comportamiento necesarios, incluso a través del mandato legal, es uno de los proyectos globales más críticos de este tiempo.

Una respuesta legal y eficaz al cambio climático requiere la atención intensiva de especialistas dedicados a comprender las profundas implicaciones de lo que podrían parecer diferencias sutiles en el lenguaje legal o reglamentario; las formas en que se puede aplicar la ley para abordar este fenómeno global.

¿Qué es la litigación climática?: Litigios sobre cambio climático. "Aquellos casos que han sido partería ante instancias administrativas, judiciales o investigativas, que presentan cuestiones de hecho o de derecho, de aspectos científicos del cambio climático o esfuerzos de mitigación y adaptación". (...) excluye casos donde la discusión sobre el cambio climático es circunstancial e irrelevante para el futuro de la legislación relativa al cambio climático. (PNUMA, 2017, El estado del litigio en materia de cambio climático. Una revisión global. p. 10 y 11$)$.

Contenido:

>984 casos: 654 casos en EEUU y 230 en el resto del mundo (PNUMA, 2017). 
ENFOQUES JURIDICOS

REVISTA MULTIDISCIPLINAR DEL CEDECS

ISSN 26832070

Número 03

enero-junio 2021
Reseña: “Litigación climática”

María del Rosario Huerta

DOI: https://doi.org/10.25009/ej.v0i3.2564

1562 casos: 1.213 casos en EEUU y 359 en el resto del mundo (US Climate Change. Litigation fecha base, Sabin Center for Climate Change Law at Columbia LawSchool) http://climatecasechart.com/about/

- 374 casos en el resto del mundo y 13 casos en España (Climate ChangeLitigation of the World of Grantham Research Institute on Climate Change) https://climatelaws.org/cclow\#map-section

Diversos casos ordinarios y pocos casos estratégicos.

Tipo de litigación climática:

En función de los tribunales: organismos nacionales de control de cumplimiento e Internacionales globales.

En función de las partes: Entre particulares. Entre entes públicos. Entre entes públicos contra particulares.

Situaciones jurídicas protegidas:

Normativa internacional. Protección de derechos humanos. Derechos civiles. Derecho humano al medio ambiente. Public trust (common law).

Actuaciones recurribles: Normativa y planes sobre cambio climático. Actos administrativos. Inactividad administrativa. Principio de separación de poderes.

Capacidad: Personas jurídicas. Las ONG. Personas físicas.

Legitimación: Grupos sin personalidad jurídica. Naturaleza.

Pretensiones y contenido de las sentencias: Reparaciones convencionales / modificaciones de políticas climáticas. Estimatorias. Principios generales. Relación de causalidad. Principio de precaución. Consenso científico. Concreción objetivos de mitigación. Concreción objetivos de mitigación. Falta de justificación del estado de niveles más bajos. Ponderación de intereses (en particular, objetivos mitigación. Leyes cambio climático). Mayor intensidad del control judicial por los derechos humanos.

Para búsquedas personalizadas de la base de datos se pueden aplicar varios filtros para crear consultas específicas. Los enlaces están disponibles para acceder a la documentación que integra cada caso. Se incluyen los enlaces que contienen decisiones, quejas y otros documentos. Por ejemplo, una búsqueda de casos en los que algún órgano del Estado Mexicano es parte de un procedimiento jurisdiccional o administrativo en materia de 
ENFOQUES JURIDICOS

REVISTA MULTIDISCIPLINAR DEL CEDECS

ISSN 26832070

Número 03

enero-junio 2021
Reseña: “Litigación climática”

María del Rosario Huerta

DOI: https://doi.org/10.25009/ej.v0i3.2564

cambio climático, nos arroja los siguientes casos que se transcriben a guisa de mostrar la funcionalidad operativa de este sitio. A saber:

México: Tribunal de Distrito en Asuntos Administrativos

Greenpeace México c. Ministerio de Energía y Otros
Estado: Pendiente
Categorías de casos:
Demandas contra los gobiernos Derechos Humanos
Jurisdicciones:
México Tribunal de Distrito en Asuntos Administrativos
Leyes Principales:
México Ley de la Industria Eléctrica
México Constitución
En litigio: Si la política del sector energético de México viola los derechos humanos al
promover los combustibles fósiles a expensas de las energías renovables
Jurisdicciones: México Tribunal de Distrito en Asuntos Administrativos.
Juventud v. Gobierno de México
Fecha de presentación: 2020
Estado: Pendiente
Categorías de casos:
Demandas contra los gobiernos Reducción y comercio de emisiones de GEl Otro
Jurisdicciones:
México Tribunal de Distrito en Asuntos Administrativos
Leyes Principales:
México Ley General del Cambio Climático
México Constitución
En cuestión: Los jóvenes buscaron la acción climática por parte del gobierno federal.
Jurisdicciones: México Tribunal de Distrito en Asuntos Administrativos.

México: Suprema Corte de Justicia de la Nación

Resolución sobre la modificación de la regla de combustible de etanol

Fecha de presentación: 2019

Información del reportero: 610/2019

Estado: Decidido

Categorías de casos:

Demandas contra los gobiernos Derechos Humanos

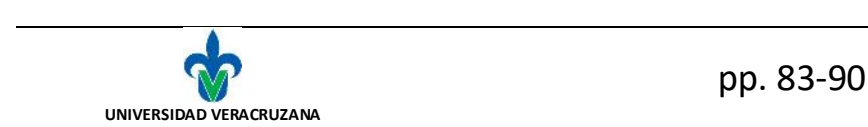


ENFOQUES JURIDICOS

REVISTA MULTIDISCIPLINAR DEL CEDEGS

ISSN 26832070

Número 03

enero-junio 2021
Reseña: “Litigación climática”

María del Rosario Huerta

DOI: https://doi.org/10.25009/ej.v0i3.2564

Jurisdicciones:

México Corte Suprema

Leyes Principales:

México Constitución

Resumen:

El 22 de enero de 2020, la Corte Suprema de México invalidó una acción de la agencia que habría permitido un mayor contenido de etanol en la gasolina. El Tribunal de Justicia concluyó que el principio de precaución y el derecho a un medio ambiente saludable requieren la consideración de los riesgos medioambientales del etanol, incluidas sus contribuciones a las emisiones de gases de efecto invernadero.

Una navegación por estos sitios de la red nos avisa y advierte del estado de la Justicia y el Derecho en un mundo determinado y acotado por los efectos del cambio climático. El poder judicial puede controlar y compeler para que los poderes legislativos y ejecutivos actúen de forma más decidida en la lucha contra el cambio climático y, excepcionalmente sustituir sus decisiones. Cada vez hay una mayor concienciación de los jueces (formación e información). Los litigios son una herramienta más en la lucha contra las incidencias adversas del clima. Por último, la movilización social, a la par de la información electrónica y la investigación académica, son recursos imprescindibles para garantizar la efectividad de las acciones procesales de los tribunales en el tratamiento y decisión de los casos derivados de la emergencia climática. 
ENFOQUES JURIDICOS

REVISTA MULTIDISCIPLINAR DEL CEDECS

ISSN 26832070

Número 03

enero-junio 2021
Reseña: “Litigación climática”

María del Rosario Huerta

DOI: https://doi.org/10.25009/ej.v0i3.2564

\section{Fuentes de consulta}

Climate Change Litigation of the World of Grantham Research Institute on Climate Change. (2020). London School of Economics and Political Science. Recuperado de https://www.Ise.ac.uk/grantham-research-institute

PNUMA. (2017). El estado del litigio en materia de cambio climático. Una revisión global. p. 10

$\mathrm{y}$

11.

Recuperado

de https://wedocs.unep.org/bitstream/handle/20.500.11822/20767/The\%20Status\% 20of\%20Climate\%20Change\%20Litigation\%20-\%20A\%20Global\%20Review\%20\%20UN\%20Environment\%20-\%20May\%202017\%20$\% 20$ ES.pdf?sequence=7\&isAllowed=y 